\title{
Building, Testing and Assessing a Learning Management System
}

\author{
Luigi Colazzo and Andrea Molinari \\ University of Trento - Department of Computer and Management Science
}

\begin{abstract}
This paper summarizes the experiences of our research group in managing the full process of building, testing and assessing a Learning Management System for an educational institution. We will show how we moved across the "make or buy" dilemma that normally educational institutions have to face when deciding to implement a support for online and distance learning activities. We will deal with this theme by referring to systems and prototypes developed by our research group. Specifically, we will describe our experiences in realizing systems for making didactic material available on the Internet, such as in the Learning Management Systems - LMS. This experience is based on what has been developed, tested, and put to use in some faculties of the University of Trento, where non-traditional learning environments in which students require more than the traditional faceto-face lessons are becoming ever more important. The prototypes produced are based on platform-independent technologies, and they make it possible to broaden one's horizons, even for those students, such as lifelong learners, who want freedom from time constraints and also freedom from some technological constraints that are imposed by some forms of distance education currently available on the market. Some extensions to mobile tools like PDA, tablet PC, cellular phones etc. are presented, with regard to the impact of their introduction on the LMS and, in general, on the information system of the institution.
\end{abstract}

Keywords: Learning Management System, online learning, mobile education.

\section{Introduction}

The point of departure of our argument is the reality, often overlooked by authors, that to teach in a university context it is necessary to use different approaches, depending on the subject area covered. For example, teaching history of philosophy in a Humanities program is vastly different from teaching a technological discipline such as database management in a computer science course, without even considering the content itself. In a history of philosophy course, the knowledge to transmit is generally of little importance (rarely more than biographical information on the authors and their relationship to the culture of the time): what really counts is equipping the students to engage in critical discussion on the questions raised in a philosophical debate of the past, and also to be able to recognize the influence of that debate on issues currently under discussion in philosophy. Diagrams and visual material are essentially nonexistent, while lectures are fundamental, as are reading and writing.

On the other hand, in a database course the ideas to transmit are numerous and complicated; to know the essential facts and to understand the techniques of organizing a database are much more important than to develop the capacity to discuss the current research issues in database management (these are the typical topics covered in a PhD course). In this type of course it is necessary to teach students how to interact with complex systems (DBMS) and with programming languages. Consequently, some specific tools which can be used in both teaching environments will be of greater or lesser importance, depending on the subject taught. For example, an electronic discussion forum in the first case would be essential, while the management of FAQ would be of little importance. In the second teaching situation, a discussion forum could be useful, but a high number of FAQ is indispensable. Superficially, these divergences can be seen merely as different approaches (lectures vs. constructivism), but it is not so simple; in reality, teachers in both disciplines probably adopt a constructivist approach, but the real difference lies in the nature of the 
knowledge area. A discussion forum is an excellent tool within a constructivist approach to the study of a philosophical discipline, and, indeed, this constructivist approach was already used long before now: the Socratic maieutic was, in fact, a constructivist approach.

A second issue regards the reasons why it is necessary to use electronic support tools in university teaching. The usefulness of using Internet to disseminate didactic material stems not only from the fact that students can take advantage of this learning opportunity from a distance, but also from the fact that this method works particularly well with different teaching and study schedules. In other words, with the exception of systems dedicated to distance learning, where flexibility in organizing study and other commitments is important for the student, it is undesirable to maintain distance between teachers and students. This aspect is of fundamental importance for lifelong learning, where the educational experience goes beyond (in time and place) the physical educational institution, in both work and personal life. In this sense, the possibilities take on a new form, the student-institution relationship changes considerably, the interests of the user (student) are more diversified and less focused on the physical presence of the teacher at a lesson - even a distance lesson - and are more focused instead on having a well-organized course with easy access to and retrieval of the course material. Mobile technologies like cellular phones, PDA, tablet PCs, smartphones, UMTS etc. indicate that mobile users will need different models of learning that adapt to their being in movement and to their fragmented use of time.

The validity of distance learning has been widely debated for some time, particularly within the university context [1] [2], starting from the early experiences with CBL systems [3] until the advent of Internet [4] and the modern integrations among various media in real-time during the lesson [5]. This use of e-learning systems differs notably from the typical distance learning (DL) situation. As a consequence, even if the technologies used may be identical, the aims and objectives are significantly different. The underlying idea of DL is to compensate for the absence of the instructor who, for reasons of distance or time, cannot be in the physical presence of the learner. Systems of DL aim to adapt to this reality by working towards four objectives:
- To "virtualize" the instructor's function (the traditional lesson of the teacher thus becomes a registration);

- To "virtualize" the class (the students are a "class" only in a virtual sense);

- To prepare learning objects adapted for selfstudy and for different supports with different screen resolution, eventually incorporating the standards for creation of didactic material, such as the IMS project [6], the LOM [7] and SCORM [8] models, etc.

- To create a feedback channel (negative $=$ corrections, positive $=$ encouragement $)$.

The issues are inherently different in traditional learning environments. The instructors and students enjoy a real and tangible relationship; technology is not used as a surrogate, but rather as an extension of communication already taking place - it "overflows" into the virtual world. The situation in this case is substantially different from that of distance learning, for several reasons:

- the instructors are "real";

- the students are "real";

- study is guided and self-study represents only one portion of the overall learning experience;

- feedback channels are more frequent and can be both official and less formal, non-official in form and content.

In these situations an academic institution such as a university faculty is represented as an aggregate of the didactic processes organized by an academic institution. We deal with this aspect of the problem in this paper. We present the larger technological scenario being referred to in the paper, briefly presenting learning communities and varying communication situations in which communication technologies are merely an extension of natural communication. A course, for example, constitutes a small real community that gathers for a designated period of time during which a teacher, a specific number of tutors and the learners embark on a learning process. Also regarding this notion, see [9], where the idea of community as an outcome of working within an online environment is discussed. If everything works according to plan 
and schedule, the outcome of the process is an increase in knowledge for everyone involved. In modern terms, it is no accident that the words community and communication have their roots in the Latin word communis, meaning to work together (com) for a public good (munus). A community that fails to communicate ceases to exist as a community. In other words, the learning communities that an academic institution organizes use technology to broaden their possibilities for communication and, as such, the system of e-learning becomes the means to a greater end.

To discuss these issues more deeply, we present the research and experiments conducted at the University of Trento in the last four years. First we will look at the characteristics of a clientserver service, typical of the Learning Management Systems previously mentioned, which is created from scratch as an alternative to acquiring a system already on the market. In this context we analyse the importance of the project "Faculty on-line", specifically noting the organizational peculiarities that lead it to decide whether to "make" or "buy" the service. In section three, we demonstrate the necessity for this type of system to have personalized communication channels for every actor in the educational process. These tools have been developed principally to maintain contact with the students deciding to extend their study programme beyond the standard time period, and who perhaps cannot participate actively in the daily life of the faculty, or for those students having interests or goals different from those of the traditional student. In the fourth section we present the system developed at the Faculty of Economics at the University of Trento as an example of what is required in building this type of educational systems. The fifth section shows the results of the assessment procedure we built in order to understand the level of satisfaction in using the system reached by all the kinds of users. Last section will be devoted to explain the extensions toward mobility we are implementing in the system, thus integrating a traditional LMS with all devices, tools, models and problems related with people on the move.

\section{The Faculties, Central Institutions in University Education}

University studies in Italy take place predominantly in public institutions whose characteristics and organization are defined by federal law. The study programs offered by the universities are grouped by faculties, and the faculties are, therefore, the organizational structures that materially combine educational offer into homogeneous disciplines (Science, Humanities, Engineering, Economics, etc.). It is worth noting that in this system the faculties are responsible only for teaching, while scientific research is organized by other entities, notably the departments. The departments are designed to be the centers of research only; therefore, they have no input in the organization of courses, just as the faculties have no power to intervene in research issues and activities. In short, a person in Italy is a member of a faculty only in the role of a teacher and is a member of a department in the role of a researcher. On one hand, this situation intersects with the teaching process (a person can run different courses in different faculties) while on the other hand it has a definite influence on the administrative management of the faculty, and, therefore, on what can be called the "back office" of a university faculty. The educational system of a faculty is roughly divisible into three areas of management, these being:

- management of the teaching staff,

- administrative area,

- area of didactic management (for example, a LMS).

The instructional information system based on faculties assumes that these three areas are heavily intertwined, as shown in Figure 1.

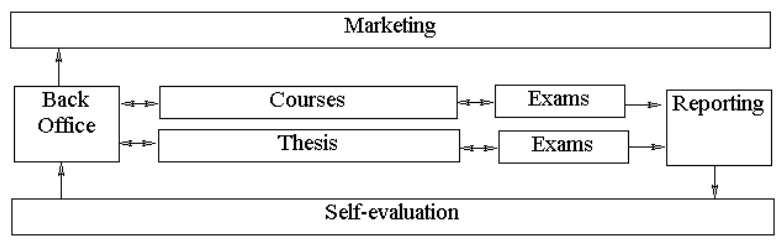

Fig. 1. The different aspects of a Faculty-based Information System.

The material organization of courses is handled by the staff of the dean (back office); the 
staff executes the decisions of the faculty committee regarding educational programs, specific courses, and teachers. The personnel of the faculty also take care of marketing, as well as of handling feedback information on the didactic activity so as to help the teachers to conduct self-evaluations, and also to evaluate the faculty in general. The principal responsibilities of the teachers are coursework and thesis guidance, in addition to the ongoing work of evaluating student performance (exams). It is obvious, then, that what is traditionally considered to be didactic material in electronic form (Courseware) is really part of a much larger instructional system into which it becomes integrated.

In order to solve the above problems, the Faculty of Economics of the University of Trento decided to start the implementation of part of the overall picture of a Faculty-based Information System. The project took off in late 1999: we firstly established which functionalities should have been provided and if the system could have been found on the market or should have been built ex-novo. Now we will briefly discuss this last issue. At the evaluation stage, it was important to investigate costs of building a system using internal resources. This was because, although there were strong reasons for purchasing an off-the-shelf Learning Management System, such as TopClass ${ }^{\mathrm{TM}}$, Lotus Learning Space ${ }^{\mathrm{TM}}$ or WebCT ${ }^{\mathrm{TM}}$, there were many successful instances where universities developed a system by themselves. It was evident that homegrown systems were often more tailored to a university's specific needs. For an analysis of this, see [10] [11]. LMS are being promoted as a means of simplifying the creation and management of instructional websites. There are many studies that seek to compare between specific courseware management tools (e.g. [12]; [13]), but it seems that the efficiency and effectiveness of these tools with respect to customized Web based systems is less easy to define. Summarizing, we decided for the "make" alternative with the following motivations.

- The cost: the systems that manage, distribute and maintain the on-line learning materials are high-cost systems that imply also other secondary costs, like adequate hardware and assistance.

- The skills: LMS are complex to understand and manage, so normally some personnel should be devoted to their management. We were not in the position to use resources for this task: the Faculty has no personnel to be used and instructed on such environments.

- Some specific end-user needs, in particular the integration with administrative and bureaucratic functions in the perspective of an integrated Faculty-based Information system: many of the functionalities that normally relate with the didactic activity of the teacher are closely related with administrative tasks that should be carried out in specific way and time, thus constituting a big constraint for packaged systems that have no personalization features or that need a deep knowledge of personalize. Moreover, in a highly competitive market like the one involving educational institutions, having a personalized system on which we are able to perform every change and improvement we prefer, is undoubtedly a great competitive advantage.

- The time: a prototype should have been ready for the second part of the academic year 2000 (march 2001) with a pilot group of teachers and students, and a beta version of the system was to be used by all the teachers and students in the first semester of 2001. This schedule was not compatible with our implementation of an LMS like the ones cited above.

For all these reasons, we decided to build the system internally, creating only what was needed. The main objectives of the project were the following:

- to allow the teacher to keep a constant relationship with his/her students, in the different ways that will be explained in the following sections;

- to allow the teacher to distribute educational material to students;

- to keep the data for administrative and reporting tasks to be performed by the teacher and by the secretary of the Faculty.

\section{Functional Requirements for On-Line Courses}

The use of the Web as a tool for didactic activity has proved particularly useful in recent 
years [14]. Courses offered through the Web are a very common practice now in teaching [15], offering different opportunities for interaction between teacher and student. These systems are often used to support distance learning, but in this case the objective is different. The aim, in fact, is to use electronic communication to improve the traditional way of instruction. This goal makes the following assumptions:

- there is a real course that prescribes a schedule, meeting place, lectures or other activity (exercises, project work, drafting and completing papers, experiments, etc.),

- teachers, tutors and students interact regarding the coursework,

- all courses have rules regarding how coursework activities must be carried out and regarding the assessment of results,

- students attend more than one course at a time and, therefore, are doing coursework in different disciplines,

- teachers give lessons in different topics and at different levels, possibly in the same academic period,

- teachers can be assisted by a certain number of tutors.

A system that makes it possible to combine the normal channels of communication (their existence is presupposed by the system described) with opportunities for electronic communication must respect some general requirements to guarantee a certain level of effectiveness. The principal requirements are configurability, scalability, modularity, accessibility, usability and freedom of choice. We now offer a brief discussion of each requirement.

a) Configurability: Each edition of a course has its own history. In fact, courses change in relation to the classes, time, developments in the field of study, interests of the teacher as well as the labor market. It follows that in a support system based on electronic communication, each single edition of a course should have its own virtual space (for example, the Home page of a Database course, second semester, academic year 2001-2002). The teacher working with the system should be able to configure every edition of a course with appropriate communication mechanisms. Some of these exist by default (course syllabus, lesson schedule, etc.) while others can be used by choice, if deemed necessary or useful (chat forums, video conferencing, message board, newsgroups, etc.). Also, students need to configure their own virtual environment, because not all students follow the same courses at the same time. In the end, the number of students per course is not uniform (in Italy some university courses have hundreds of students and others very few): a significant change in course enrollment has important consequences on how electronic communication can be organized. In practical terms, for example, a teacher of 200 students would be wise to limit the use of e-mail so as to avoid spending an inordinate amount of time responding to student enquiries.

b) Scalability. In the real university context there are small faculties (with few study programs and students) and large faculties (with several study programs and large numbers of students). In some cases the technological support infrastructure that we have briefly described is not completely present, or the communication channels within the university network differ from those available privately to the students.

c) Modularity. A network at the university level is almost never constructed with the same components: it is more likely built over time, in layers, and with varying growth patterns and, therefore, varying capabilities. To have a monolithic system with a uniform technological infrastructure is not a realistic expectation, at least in the majority of cases in Europe. Moreover, the naturally occurring differences in teaching methods among diverse faculties in the same university suggest architectures constructed with models that are duplicated on different machines, and also distributed databases. It is worth remembering that faculties are almost always located in different buildings, and in many cases there may be more than one branch of the university or faculty, perhaps located several kilometers away.

d) Accessibility. If possible, the system should be accessible from every Internet access point. This means not only from computers available in university buildings but also from any other location and from mobile devices. In fact, university teachers often travel for research, per- 
sonal study, participation in scientific meetings, and, in addition, they obviously do not have access to the internal campus network from their home. The same is true for students and teachers, albeit for different reasons. Furthermore, electronic communication opens the door to new learning experiences, such as a course in which academics from all over the world contribute in different ways (through video conferences, with on-line lectures in real time, with asynchronous contributions to discussions, etc). A good system will guarantee all these at the lowest cost possible.

e) Usability. A system is obviously a failure if it is deemed unusable by the same people who should use it. The problem with these systems is particularly complex because it involves (a) the nature of the Learning Objects used in electronic communication; (b) the most general communication environment in which the Learning Objects are used; and (c) an organization of activities that guarantees correct Learning Objects at correct time for a specific learning task. The term "Learning Object" has been defined by many researchers, but the most convincing definition is that proposed by the IEEE Learning and Technology Standards Committee: A learning object is any digital or non-digital entity that can be used, reused or referenced in technologybased teaching [16]. Differing degrees among users of awareness and familiarity with the system, not to mention access issues, complicate the issue further. The advent of mobile devices such as PDA and cellular phones add new problems to usability, due to the limitation of screen size and memory of these devices.

f) Freedom of choice. The system must provide varying degrees of freedom at different levels. The requirements for configuration, scalability, and modularity partly contribute to this need, but by "freedom of choice" we refer to something more all-encompassing. Using the system must not be an obligation but rather an opportunity, both for teachers and students. Moreover, technological limits cannot be imposed on the nature and complexity of the learning objects that a teacher considers useful for a course. In this case the question is no longer ideological, but also leans toward a pragmatic evaluation of academic teaching. A look at the Italian academic system reveals that the average age of the three types of teacher, foreseen by the national system is over 55 for full professors, around 50 for associated professors, and over 40 for research assistants. This means that only a small percentage of these teachers attended computer science courses during their own university studies. In fact, in Italy just 30 years ago, computer science courses were offered exclusively at the faculties of science and engineering. Consequently, everything that the majority of Italian university teachers know about computer science has been acquired through ongoing study (often self-study) during their professional academic career. Similar observations can be made about other European realities, as made in [17], and perhaps for a large part of higher learning, even on a global scale. Also, a Learning Object is by nature variable, ranging from a simple electronic text to a complex role-play in real time; this is discussed further in [18], [19], [20]. Therefore, no limits may be imposed on the technological realization of Learning Objects.

In the next section we describe the functions of interactive On-Line Teaching System, developed by our group at the Faculty of Economics, University of Trento.

\section{An Interactive On-Line Teaching System}

The system we are presenting has been operational for about three years at the Faculty of Economics of the University of Trento. The faculty has approximately 3000 students and a few hundred teachers. From an architectural perspective, the system is an application of dynamic Web pages: in other words a DBMS and other generalized systems are integrated so as to maintain an environment favoring communication and self-organization of the work using a browser. The system offers its services principally to three different types of actors: teachers, students and administrative staff. All actors are recognized by the system and for each actor the system offers a personalized environment to access the selected functions. A difficult choice, nowadays still under discussion, regards the fact that the system should be open to everyone or accessible only to registered students, i.e., only to the students that regularly pay the fees. Some teachers believe that the educational 
material should be freely distributed to everyone in the world, while others prefer that only their students (freely) download the educational material. At the moment, the more restrictive vision has been adopted: the students must register in the system with their personal data and their faculty registration numbers. A new login and password is released for the registered students. The same registration procedure is made for the teacher, and it is more obvious in order to avoid that inappropriate material is loaded inside the system. There are many functions usable for each of the three actors (teachers, students and administrative personnel). We will briefly present the main functions.

The teacher can make use of several functions of the system. Having gained access with the login and password, the teacher selects a course in which to work. To avoid any confusion the courses are distinguished by year. After choosing the course, the teacher is offered different tools through which it is possible to have all the functionalities necessary to complete the tasks desired: to insert information, to update, to eliminate or to add material. Specifically, these instruments are:

- the Bulletin Board, where the teacher can insert and modify information to provide notices and information to students enrolled in the course;

- Syllabus (Figure 2), a system summarizing the content of the lesson and allowing students to identify the material relevant for a given lesson. From this page the teacher can also add a file to the lesson (uploading it on the server).

- Materials, the teacher can manage any type of material in electronic format to make it

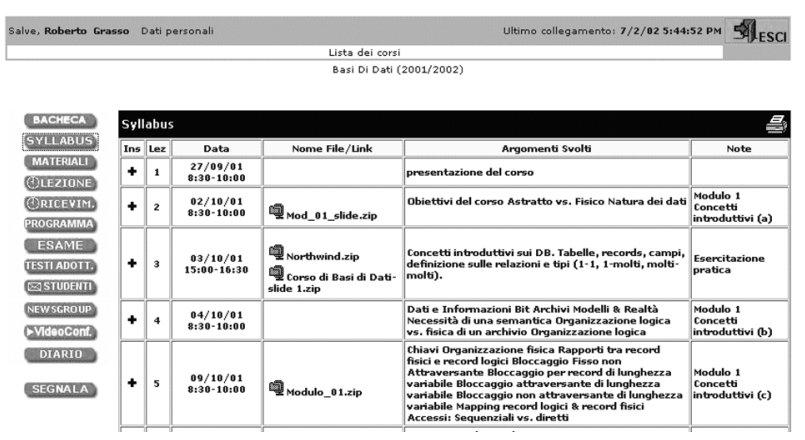

Fig. 2. Framework of the syllabus. available to students in the course. The teacher, following a prescribed procedure, can upload files from the teacher's computer to the server. The material is subdivided by category in a way that permits the user to find quickly the desired type of material; some typologies available are: notes, bibliographies, exercises, lists of links, formulas, graphics, suggested readings, commentaries, manuals, assignments, assignment solutions, etc; once an element from the list has been chosen, the user has access to the actual list of materials for that category. From here it is possible to insert, modify, or eliminate a file from that list. The teacher also has the possibility to make a file visible or not; this functionality is useful for the teacher who may or may not want to make a specific file available at any given time, as necessity dictates. (Figure 3 )

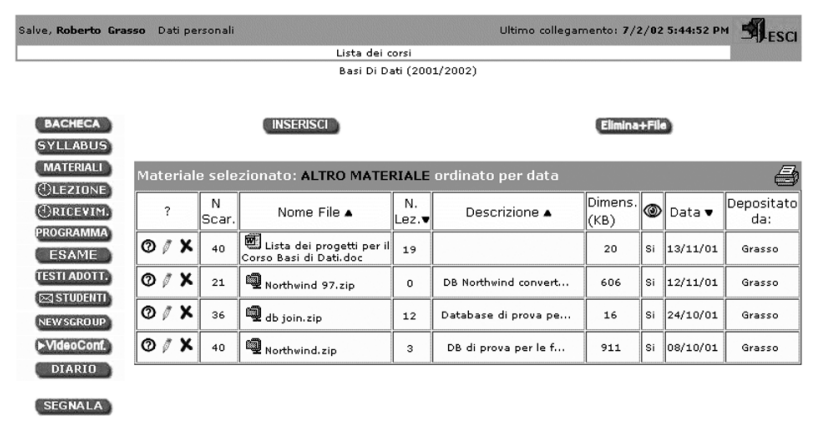

Fig. 3. List of materials.

- Timetable, the teacher can specify the lesson times and any changes to them, as well as office hours for meeting students;

- Information on the course, it is possible to specify the course program, the exam procedures, the list of texts used or suggested for the course;

- Student Mailing List, the complete list of students enrolled in the course. It is possible to use this list to send mail to some or all of the students. (Figure 4)

- Diary of the lessons (Figure 5), which differs from the syllabus in that it permits administrative functions, while with the syllabus it is possible only to upload or download files. The diary makes it possible to 


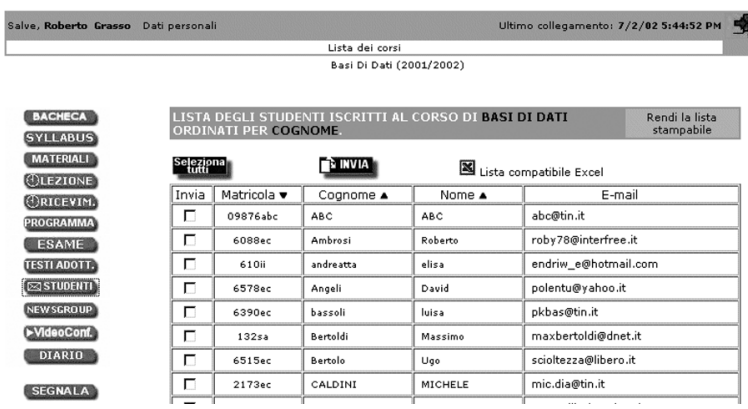

Fig. 4. Teacher Area: student list, functionalities of mailing list.

generate lessons, specifying date, time, a description of the lesson, and related notes;

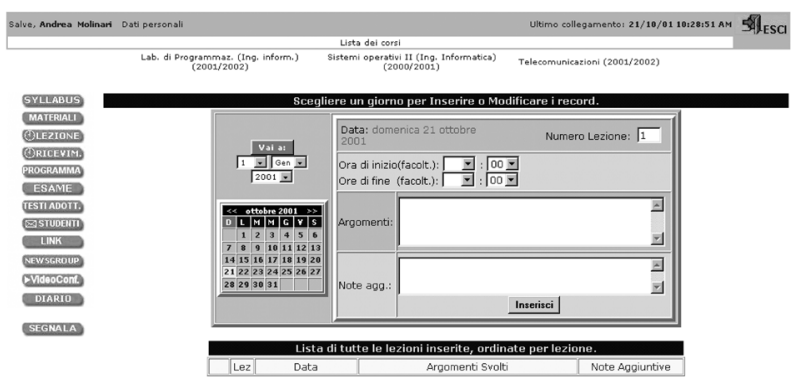

Fig. 5. The teacher's diary.

- Video-conference (Figure 6), it is possible to have a video conference, integrating a personalized version of the software Netmeeting ${ }^{\mathrm{TM}}$ internally with the Web Browser. Therefore, when the teacher accesses the video conference page, the students that are connected to the principal page of the system will automatically see a green light indicating that the teacher is on line (Figure

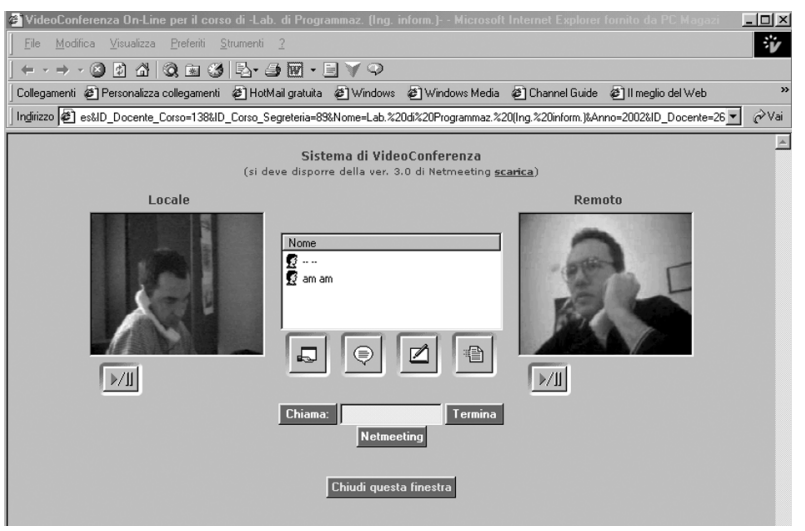

Fig. 6. A video conference session.
7 n.1) and available for a video conference. The system automatically memorizes the IP adress of the teacher, thus helping the students and teacher to overcome the technical difficulties of configurating and setting up a video conference via Internet.

- Newsgroups can be created by the teacher: this function will be described in greater detail in the following paragraphs.

The tools available to the students are generally similar to those used by the teacher, the only difference being that those available to students are usually "read-only". This means that the syllabus is usable only to download material from the server, and the course program is only visible to students who cannot modify it in any way. To have access to the course page, the student must register, that is, the student must choose the preferred courses from those on the list of the courses offered. These choices define the study area of the student, and as such determine the courses to which the student has electronic access (Figure 7 n.3). One of the most important features available to the student is the area called "News" (Figure 7 n.2).

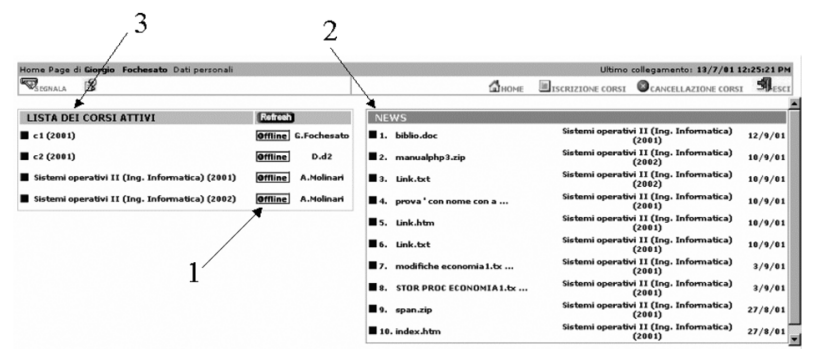

Fig. 7. The principal page of the student.

This function is made available to the student every time he or she connects to the system; it shows all the documents that have been placed on the server since the last time the student connected, for all courses in which the student is enrolled (visible, as described above, in the left-hand frame). It also shows other information placed on the bulletin board by the teacher. The student, therefore, before entering a course, can select directly a document present on the "News" list, independently of the course and without having to "dig around" the course page. This functionality helps the student greatly to be updated on events or changes taking place during the course, especially if the student is 
unable to attend a given lesson. In the near future, this function will be implemented using mobile telephones to interact with students.

Another important characteristic of the system is the Newsgroup. The validity of this tool in teaching had been widely proven. [21] [22] [23] [24] [25]. By selecting a newsgroup, the user has access to the list of related messages; the user can decide to insert a new message, read one, enroll in the preferred group, or simply view the messages by list rather than by thread. Each course can have more than one newsgroup. The teacher, once entered in a newsgroup that he or she has defined, is given the possibility to interact with the messages in different ways. As we can see (Figure 8), the messages inserted by the teacher are shown in a different color; moreover some icons can be used to point out particularly interesting messages (FAQ, censured messages, etc.). Other possibilities offered to the teacher are to cancel, modify, and grade messages, as well as to moderate the entire newsgroup. The user can decide to activate the service of preferred messages (Figure 9). This service makes it possible to periodically receive at the user's e-mail address all new messages inserted in the newsgroup.

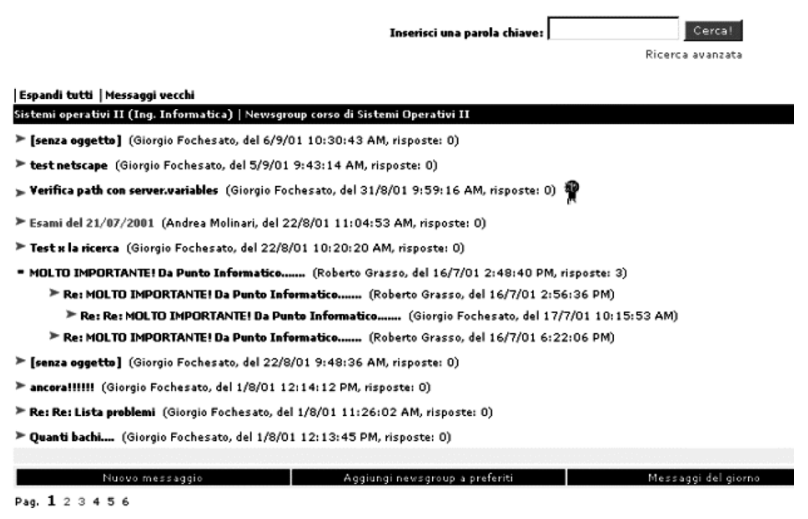

Fig. 8. The view of the messages present in a newsgroup.

Each message, whether shown in the principal, general view (Figure 8) or in a detailed view, shows the number of times it has been read (Figure $10 \mathrm{n} .1$ ). In addition, students can participate in the discussions by giving a sort of grade to each message (Figure 10 n.2); this grade can be seen by anybody, so that the importance of a single message can be weighed. As one can note from Figure 10 n.3 the typical "thread" structure is present also in the message composition phase, so as to give the user greater flexibility in interacting with other users. All messages are memorized in text files and not in database structures.

\section{NEWSGROUP}

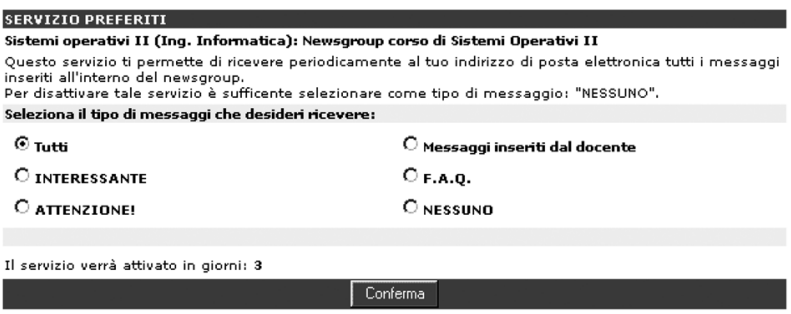

Fig. 9. The preferred service.

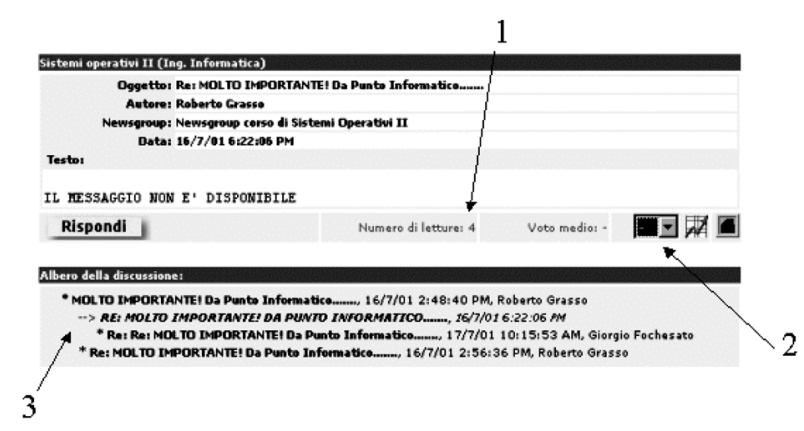

Fig. 10. A single message with the options provided by the system.

In the area of maintenance there are several functions which are indispensable for the faculty secretaries. One of these is linked to the change in academic year; each academic year, in the month of September, in fact, the courses can be changed or their titles can be changed, as well as the teachers and tutors associated with the courses to mention just a few possible changes. With the system, the secretary has a tool that can be used to redefine and update all the information related to the courses and teachers. Other instruments can be used to create new courses and provide information about these teachers, tutors, or staff related to each course. Apart from these functions, there are also tools allowing for e-mail communication with some or all of the teachers and students. Yet other functions regard the administration and management of the newsgroups created by the teachers. 


\section{The Results of Our Experiment}

As mentioned, one of the main purposes of the project was to evaluate user satisfaction in order to understand the impact of the system on the interaction between the students and the institution. To this end, we used a self-administered "Web questionnaire" with closed answers that was directed to all students enrolled in the system. Subdivided into three sections, the questionnaire has 24 questions. Besides personal data (gender, year of university enrollment, degree programme), the survey brought to light some important user feedback, organized as follows:

- in the first section the assessment is on a 10-point scale, measuring simplicity, clarity, efficiency, and power of the systems compared;

- in the second section the general assessment is again on a 10-point scale, measuring materials and information available online, for every course the user has been enrolled in;

- the third and final section measures satisfaction with the efficacy and efficiency of the system as a tool supporting teaching and learning.

The survey was carried out between June and July 2002, during which 574 students completed the questionnaire. Before describing the results it is useful to underline that the group surveyed is a "narrow slice" of the university population, and not representative of the larger student body. This is true, primarily because the sample surveyed is from the population that voluntarily decided to enroll in the system and, secondly, because nearly $98 \%$ of this group is enrolled in the Faculty of Economics - a logical outcome, given that almost all of the e-learning courses are offered by this faculty. We cannot assert that the group surveyed is a representative sample of students enrolled in or attending courses at the Faculty of Economics, because not all professors participated in the system, thereby nullifying the need for the e-learning option for their students.

We can now describe the characteristics of respondents, which are relatively evenly distributed between male $(52.3 \%)$ and female $(47.7 \%)$.
About four fifths $(81.0 \%)$ attended courses regularly and nearly all $(85.1 \%)$ had already enrolled in the system the semester before the survey. Half of the survey group $(50.4 \%)$ indicated that they were employed, which is a relatively low number when compared with graduates from the same faculty in $2001(84.0 \%$ source AlmaLaurea), who declared that they had worked while completing their university degree.

Students consulted the system frequently, at least $35 \%$ doing so at least once a day and $60 \%$ one or more times a week. The adoption of the system also led to changes in the use of Internet as a didactic tool. Before using our LMS, less than one third $(31.5 \%)$ of respondents indicated regularly using the computer to search for information for personal study, while now over four fifths $(86.6 \%)$ also consult Web pages made available by professors. The result is a full-time student in every sense of the word, who is active and takes advantage of a variety of study tools.

Unfortunately, this type of system is found lacking in another equally important aspect. The Italian university system is among the more flexible ones in industrialized countries, with low enrollment costs, compared with other countries; moreover, attendance at lessons is not obligatory, nor are there constraints on the exams methods. These facts mean that a large segment of the student population can enroll in the courses and take exams without having to attend lessons, thus being allowed to hold full-time jobs. Therefore e-learning systems are increasingly perceived as a valid alternative to support individual study for those who are unable to attend lessons regularly, or those whose studies are to some degree penalized by work commitments. Contrary to our expectations, the number of students in this category is decidedly contained. As noted, the percentage of working students is smaller than expected; moreover, only $6.5 \%$ of those who rarely or never attend lessons use the e-learning system.

We are required to look into the causes of this underuse, which, to our view, is not related to the tool itself but to how it is used. If the instructors use the system merely as an electronic notice board for distributing copies and bibliographical references, the students similarly make limited 
use of the tool as a means to support their studies. This can depend on different factors: each communication system must overcome its physical limits and create its own linguistic codes that make it recognizable and meaningful. As yet, we are not able to determine to what degree this has been accomplished, however, a notable difference exists between users and non-users, where the latter group would appear to be excluded from this generation of linguistic codes, hence from a form of communication. In other words, we are dealing with a system that fosters a form of social inequality in terms of access to resources.

On the other hand, we cannot in all truth assert that those using the system have made the effort necessary to learn to take full advantage of what the tool offers. An interesting statistic in this regard derives from the use of the discussion forum, a feature offered by the tool. While one sixth of the students $(18.5 \%)$ declared that the instructor of the course/courses in which they were enrolled had not used the discussion forum feature, only one fifth $(20.2 \%)$ of the remaining students had used the forum, one third $(33.6 \%)$ indicated no interest in the feature and just over one fourth $(27.7 \%)$ expressed other reasons for not using the tool. Poor ability to cooperate or communicate, or even inability to use the system because of the uncertainties regarding its purpose: all could work together to explain these statistics. Despite these numbers, the fact remains that as many as $82.2 \%$ of users indicated that the system was highly useful. Four fifths $(81.5 \%)$ reported that the system had helped them to clarify topics being studied; three fourths $(72.0 \%)$ mentioned being better informed of the opinions of their fellow students, and, similarly, two thirds $(68.7 \%)$ indicated that they had gained a better understanding of the instructor's position and 63\% were more able to follow the course.

Why, then, do such a small number of students make use of the tool? We could assert that there are courses that, by their nature, simply leave little room for discussion; a formula for an econometrics function is invariable, the argument would follow. But can we be sure? While the roles of teacher and student are yet to be defined, it is clear that the communication and transfer of knowledge cannot go in only one direction. Never before has the success of a work project hinged so much on the ability of the group to work together and circulate ideas. Poor communication skills, coupled with the inability to take full advantage of these types of tools, in the end means exclusion.

The system passed with top marks. On an assessment scale from 1 (poor) to 10 (excellent), the average score was 8.1. The highest scores were given to the system architecture for its simplicity of use (average score 8.5) and for the capacity of the system (average score 8.4). This also shows that the decision to "make" during the LMS acquisition phase did not prejudice the quality of the product or the satisfaction of the user. A score of 8.0 was given to the clarity of content, the responsibility which lay in the hands of individual professors. The system was found to be largely efficient (7.6) but not without some criticism; the fact that the evaluator may well have included the entire university network, which, while quite good, does nonetheless reveal inefficiencies, in the assessment could account for this somewhat lower score.

On the whole, positive scores were also recorded for the more technical aspects of system architecture. Nearly all users $(97.0 \%)$ declared that it was quite, or even very easy to locate information, and nine tenths $(91.0 \%)$ indicate that the buttons were clear and thorough. Slightly lower results were shown for the efficiency of the communication system, problems which are, as mentioned, to a larger extent due to inefficiencies in the university system than to the e-learning tool itself. In any case, four fifths $(81 \%)$ of respondents said that the connection was fast and that it was easy to download material.

A different type of assessment takes place when considering the system as a tool to support didactic activities. While the tool proves highly satisfactory for self-study, its role as a means of communication among different actors is less clear. Four fifths $(83.0 \%)$ maintain that the use of the system led to improved individual study, even nine tenths $(86.6 \%)$ affirmed that it helped them to pass an exam, while over nine tenths $(91.9 \%)$ of respondents found the system useful when gathering information about courses.

The communicative aspects of the system received lower scores. Only $58.3 \%$ of students found that the system had helped then improve 
their communication with the instructor, while one sixth $(16.1 \%)$ noted improved communication with other students (referring only to those who joined a discussion forum). This brings us back to the earlier problem, wherein the use of the system as a didactic support tool is highly effective, but as a system to support communication is found wanting. This gap has more to do with the users than with the system itself. On one hand, the professor may not know how to take full advantage of the tool, or is forced by other commitments to reduce the use of the system as a means of communication. At the same time, students may be overly focused on exams and perhaps unable or unwilling to work in groups, thereby not seeing the potential that communication among fellow students can have, even if it is only to pass an exam. In short, the system offers numerous opportunities to those who choose to take advantage of them, as confirmed by the positive scores received. Its potential is limited only to the degree that the user fails to take advantage of it, an issue to be explored elsewhere.

\section{The Future: Mobile Extensions to the System}

Mobile learning, or M-learning, has been considered as the future of learning or as an integral part of any other form of educational process in the future. Mobile learning is a field which combines two very promising areas - mobile computing and e-learning. Mobile learning could be any form of learning (studying) and teaching that occurs in a mobile environment or through a mobile device, like cellular phones, Personal Digital Assistants (PDA), smartphones, tablet PC etc.

Some studies show that introducing new forms of teaching (even if this means just using a standard tool for drawing on a PDA) make students spend more time in working on that subject, comparing to other subjects. [26] The current evolution and analyses of m-learning projects show many positive results. On the other hand, there are some doubts if this excitement is, or is not, a temporary side effect. Most of the researchers think ([27][28]) that PDAs and other mobile devices should be seen like an extension to, rather than replacement of, the existing learning tools. Moreover, not all kinds of learning content and/or learning activities are appropriate for mobile devices [29].

In order to support the experimentation of any tool or technique of m-learning, a rather complex information system is necessary. Its role includes distributing didactic material, user identification and authorization, gathering of the data relative to the user-system interaction, provisioning of mobile services etc. The platform necessary for this objective is already in place, and we have all the skills and information needed to extend it with mobile functionalities. In this regard, e-learning systems in general, and more specifically Learning Management System, are a vital component in the distance educational field. We have to integrate our LMS with two different classes of processes:

- on one hand, processes connected with the administrative (back-office) activity of a faculty (like registering exams, programming the teaching activity, theses management, bookkeeping of lecture hours, faculty marketing etc.: all such processes show important overlaps with processes managed by an LMS.

- on the other hand, technology evolution has pushed toward a strong mobility of all the actors, and has provided mobile devices (PDA, pocketPC, cell-phones, smart-phones, tabletpc) that accompany the user in his/her everyday life. Such tools can become additional terminals for a LMS, because they allow all actors (students, teachers, secretaries, dean, tutors, administrative personnel etc.) to stay in touch with the LMS wherever they are.

The number of possible applications is huge: for instance, the possibility for the administration to communicate in real time with students equipped with such devices, new forms of collaboration among students and teachers within a university course, the chance for the students to interact among them regarding the courses etc. The focus moves, therefore, from a system that is based on "offering courses" into a system based on the idea of "virtual community". A virtual community is a highly generalized collaboration space. In such a way, a course given by a teacher, a seminar, a group of students preparing their thesis with the same teacher, students working together on a project, 
etc. are all instances of virtual communities. A LMS becomes a computer-based tool that renders services to virtual communities, and must be adapted to specific needs of each particular community. We already built, over several years, a community-oriented learning portal. Starting from this existing background, we intend to experiment with various ways to support collaboration among users interconnected by mobile technologies through the already active portal based on our LMS.

Adaptation of the Learning Management System to infomobility will need different steps:

a) Extension of the traditional functions of a learning management system to the mobilecomputing needs required by the project. This will imply the creation of teacher-systemstudent interaction tools mainly based on SMS messages concerning the activities of these actors in the system. Moreover, the portal will provide an access point to the system's actors, in order to download the educational material and the self-evaluation tests produced according to the objectives of the project. Besides, different structures will be created to support research activities such as forums usable via mobile technologies, mailing lists for various users, management of some virtual communities (students enrolled in a course, participants to lab exercises etc.).

b) Distribution of educational material specifically created for the use on mobile equipment. This will regard both the educational material and the self-evaluation tests created in point $\mathrm{c}$ ).

c) Integration of the self-evaluation system into the LMS. This system will allow conducting tests on the main platforms that currently equip the most widespread PDAs on the market. These platforms will be the ones based on Symbian OS on one side (this means to involve the whole cellular phones market with the biggest world producers), and, on the other side, the platforms equipped with Windows CE, i.e. the PDAs that present points of contact with the Windows desktop environment in terms of applications and working environment. The choice of producing selfevaluation applications for both the PDAs environments is the result of our wish to extend as much as possible the experiment, and most of all to create a self-assessment mechanism that must be generalized as much as possible with respect to technological platforms, due to the extreme volatility of the market.

As regards the development of the systems, we decided on which devices to concentrate our development. This is a very important issue, as the market is continuously changing, with new products emerging every day. So, it is practically impossible to have a general mechanism for involving all possible devices currently available. We found the following devices useful for our experiments:

- GSM/GPRS cellular phones

- PDA

- Smartphones

- UMTS telephones

- Tablet PCs

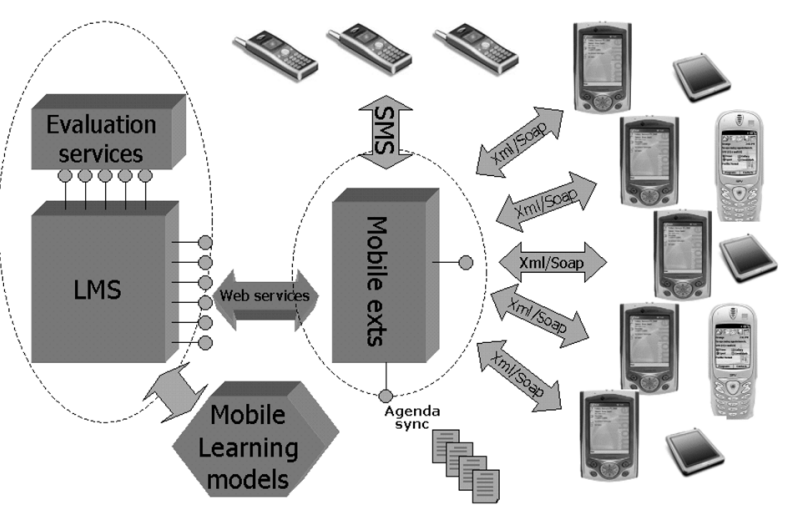

Fig. 11. Mobile extensions to the LMS platform.

The platforms have been already found in their main components. We will also experiment with the Palm OS, so that our experiment will cover a very large share of the market. In the first step of the project, however, the choice made on some Microsoft ${ }^{\mathrm{TM}}$-dependent PDAs is related mainly to the fact that most of the educational material is currently published in Microsoft ${ }^{\mathrm{TM}}$ software tools, especially PowerPoint and Word. In this sense, a device equipped with Microsoft ${ }^{\mathrm{TM}}$ operating systems will facilitate exchange of educational material already available. However, modular structure of the approach followed in building web services based on XML and SOAP will provide 
a sufficient grade of extensibility of our mobile platform to other PDAs, like those that are equipped with Symbian OS.

The test of the system will consist of some lessons conducted by Learning objects distributed by the LMS and by students and teachers utilizing PDAs, traditional viewers (like PowerPoint and Acrobat Reader) and other available mobile devices. Part of these educational materials will be available only through mobile devices: students will have to learn to study only on PDAs. In this way, different groups that have studied on different devices with different approaches will be available for our research: those who followed face-to-face lessons, those who studied on learning objects without following the lessons and those who studied on mobile devices. By creating a specific and calibrated set of tests, we want to verify the level of learning of the single groups, by analyzing the differences and relative motivations. The results of these tests will be matched with the results of the self-evaluation tests distributed to the students, in order to thoroughly verify the level of learning reached by the students. Reactions of the students will also be analyzed, especially those related to problems in studying with a new, but limited tool like a portable device. For this purpose, a forum on the web will be specifically activated, and some tutors will be available in order to help students with practical or technical problems.

Regarding the use of specific tools available with mobile technology, the most evident problem we faced in the design phase was the choice of the technology to be used to build the tools provided to the client in order to use our services. The current project provides ten different classes of services to mobile users, but in order to simplify the choice, we decided to concentrate initially on two different services for mobile devices:

- Management of SMSs sent by teachers to students or by administrative staff to teachers and students when particular events happen (meetings, reminder of expiration dates etc.)

- Consultation of a common agenda (we call it organizer) that will be available on the mobile device and will keep all the important dates for the actor (mainly students and teachers)
The first service is quite simple to build, but not so easy to manage, if the LMS that operates behind the scenes does not have all the information needed. The main problem was found in allowing the right person to send and receive SMSs, and in granting this permission inside correct boundaries, in terms of the number of SMSs sendable by the user. The second service is under development and is more complicated, as it involves one of the most difficult tasks to manage inside an LMS, i.e., time management. We are currently building a system that allows students and teachers to connect with their mobile device and consult their agenda, dynamically built with all the events that could happen during a normal university activity. This implies a great effort of abstraction and integration between the LMS platform and the mobile devices. We have evaluated five different alternatives to build the interaction between the PDA (the platform chosen for the experiment) and the central database. The problem is related to the way the client (the PDA) interrogates the remote server module, requesting the update of events since last connection. These are the alternatives we evaluated and tested, from the simplest to the most complicated ones:

- Using the embedded browser of the PDA to navigate through the web pages that web users will see using the traditional browser available for desktop PCs. This is the simplest solution, both for the users and for the development team. Only a particular attention to screen adaptation is necessary in order to concentrate the most important information on the left-uppermost part of the screen and to avoid the necessity of frequent scrolling. The web page will be created using device-specific tags and languages, like the .NET ${ }^{\mathrm{TM}}$ mobile toolkit, in order to navigate through the data available on the server. However, we decided not to follow this solution as the primary one, because of the necessity for the user to be constantly connected to the Internet to navigate through the organizer, thus requiring permanent connections (like WI-FI settings) or significant expense for both students and teachers when connected to the net using GPRS technology. In Italy, this solution is very costly at the moment, and WI-FI technology with wireless LAN is still in its infancy. Other 
short-range connection solutions have been abandoned, as we want this service to be used outside the campus.

- Using a client database application built specifically for mobile devices, that interrogates the server DB through the Internet, synchronizing the data on the mobile device. This is a proprietary solution bounded to the backend DB used and the availability of an Internet connection on the PDA that requires also quite complicated settings from the enduser perspective. However, from our tests, this solution has the advantage of dramatically boosting performance, thus reducing the connection times.

- Synchronizing the PDA with the central database and the agenda of the user by using cradles and database synchronization: this solution will solve a lot of issues, but creates a problem in terms of cradle availability around the campus, and especially the problem of supporting different cradles for different models of PDA.

- Building a client/server application in which the client (on the PDA) uses traditional RPC/ RMI mechanisms to invoke server methods in order to receive the data. This has the advantage of requiring short-time connection to the central system and could be personalized to the PDA device. The disadvantage of this solution is the proprietary mechanism of communication between server and client, and also the necessity of using particular TCP/IP - UDP ports that could complicate management of the security on the server side due to firewalls.

- Building a web application that requests a web service through the use of XML/SOAP messages to the server. This is the best solution we have found, as it provides the access in short time to the central database through the use of an open technology like XML/SOAP, will use a port that is already opened for web access, and, finally, will guarantee extension of the client part to other PDAs, simply by creating a new client interface to the web service. We will, therefore, provide the agenda synchronization through a web service that will recognize the user, verify the state of his/her agenda, and will send an XML-formatted packet of data regarding last events in the system. The client side of the application, specific for the device, will format this data for the display: after that, the connection with the server will be closed and the navigation on the agenda will be completely off-line.

\section{Conclusions and Lessons Learned}

Summarizing a four years project involving more than twenty developers and analysts, and an entire faculty with more than 3.000 students and 200 teachers is quite difficult. In this paper we presented our experience in building what we, after four years, like to call a "Learning Information System" rather than a more traditional "Learning Management System". This is due to our most evident finding of the project: introducing a system that manages the educational process (as a whole) of an educational institution does not limit its effects to the most specific didactical aspects of the institution. Introducing self-made, personalized, customized educational management system could in such situations lead to a radical change of the whole information system of the institution, which enormously amplifies the possibility of interaction with different actors (students, teachers, staff, tutors etc.). We followed this approach by building from scratch our Learning Management System and, after that, we improved it by adding different functionalities and tools based on a spiral development model and on subsequent refinements of the system suggested directly by the users. This way of building, testing and assessing the system has proved successful, also allowing us to provide users with interesting management features on the processes that happen inside an educational institution For example, one of the most highly appreciated "sideeffects" is the ability to monitor the system from different viewpoints, thereby providing interesting and useful information regarding the learning process and the behaviour of actors engaged in the system - all viewed from within an extended version of the system itself. This opens numerous opportunities for future development of the system, extension of virtual communities at varying levels among the actors involved in the system - teachers, students and administrative personnel. 


\section{Acknowledgment}

We would like to thank all the collaborators and students in the Laboratory of Maieutics for helping us start and conclude this huge work despite all the difficulties of different types we encountered. Thank you once again.

\section{References}

[1] AndERson, T., Integrating Lectures and Electronic Course Materials, Innovations in Education and Training International, 34(1), pp. 24-31, 1997.

[2] Brook, C., Oliver, R., Supporting The Development Of Learning Communities In Online Settings, in Proc. ED-Media 2002, Denver, CO, USA, June 24-29, 2002.

[3] Helic, D., Maurer, H., Scerbakov, N., WebBased Training: What Do We Expect from the System, Proceedings of ICCE 2000, Taiwan, pp. 1689-1694, 2000.

[4] Gaines, B. R. AND SHAw, M., Institutional Transformations to a Learning Web, in Proceedings of ED-Media/ED-Telecom, the World Conference on Educational Multimedia/Hypermedia, T. Müldner and T.C. Reeves (Eds.), Association for the Advancement of Computing in Education, 1997.

[5] IEEE P1484.12 Learning Object Metadata Working Group [http://1tsc. ieee.org/wg12]

[6] IMS Global Learning Consortium, Inc. [http://www. imsproject.org/]

[7] Morrison, G. AND McPheE, S., The Changing Roles of Faculty in the Course Development Process, in Proc. of ED-Media/ED-Telecom, T. Müldner and T. C. Reeves (Eds.), AACE, Calgary, Canada, June 1997.

[8] Smeaton, A. F., Using Hypertext for Computer Based Learning, Computers and Education, 17(3), pp. 173-179, 1991.

[9] ADL SCORM (2001), Sharable Content Object Reference Model Version 1.2 Specification, Advanced Distributed Learning, available at www . adlnet.org

[10] AgGarwal, A., (Ed.) Web-based learning and teaching technologies: Opportunities and challenges, Hershey, PA, USA, Idea Group Publishing, 2000.

[11] McMahon M., LuCA J, Courseware Management Tools and Customised Web Pages: Rationale, Comparisons and Evaluation, in Proc. ED-Media 2001, World Conference on Educational Multimedia, Hypermedia and Telecommunication, Tampere, Finland, June 25-30, 2001.
[12] Infoworld Publishing Company (1998), Web -based Training Solutions, http://wwwinf oworld . com/ cgibin/displayTC.pl?/981123comp.htm

[13] PC Week (1997), Computer-based training on the Web, http://www8.zdnet.com/pcweek/ reviews/0818/18ibt.html

[14] Teare, Richard, Davies, D. \& SAndelands, E. The Virtual University: An Action Paradigm and Process for Workplace Learning, London, UK, Cassell Academic, 1999.

[15] A'HERRAN A., Integrating a course delivery platform with information, student management and administrative systems, in Proc. ED-Media 2001, World Conference on Educational Multimedia, Hypermedia and Telecommunication, Tampere, Finland, June 25-30, 2001.

[16] IEEE Learning and Technology Sandards Committee, URL: [(last visit 26-02-2002) http:// ltsc.ieee.org]

[17] Aufenager, S., Teacher Education by Hypermedia Learning Enviroments - An Example from Germany, Ed-Media, 2000.

[18] Koppi, T., Hodgson, L., BAYLy, J., The Often Missing but Essential Component for Online Learning: a Learning Resource Catalogue, ED-Media, 2000.

[19] Hodgson, L., KopPI, L., Universitas 21 Learning Resource Catalogue using IMS Metadata and New Classification of Learning Objects, Ed-Media, 2001.

[20] Wiley, D. A., Nelson, L. M., (1998) The fundamental object, URL [(last visit 26-02-2002) http://wiley.ed.usu.edu/docs/fundamental .html]

[21] Collis, B., KNEZEK, G., (1997) Teaching and learning in the digital age-research into practice with telecommunications in educational settings Eugene, OR: International Society for Technology in Education.

[22] Eastmond, D. V., Alone but together: Adult distance study through computer conferencing, New York, USA, Hampton Press, 1995.

[23] Hanna, D. E., Glowacki-DudKa, M., CONCEICAO-RUNLEE, C., 147 Practical tips for teaching online groups: Essentials of Web-based Education, Madison, WI, USA, Atwood Publishing, 2000.

[24] Horton, S., Web teaching guide: A practical approach to creating course Web sites, Yale Univ. Press, USA, 2000.

[25] PAlloff, R. M., PRATt, K., Building learning communities in cyberspace: Effective strategies for the online classroom, San Francisco, CA, USA, Jossey-Bass, 1999.

[26] DVOraK, J. D., Burchanan, K., Using Technology to Create and Enhance Collaborative Learning, Proc. of ED-Media, 14th World Conference on Educational Multimedia, Hypermedia and Telecommunications, Denver, CO, USA, June 2002. 
[27] KuKulsKa-Hulme, A., Cognitive, Ergonomic and Affective Aspects of PDA Use for Learning, Proceedings of the European Workshop on Mobile and Contextual Learning, pp. 32-33, Birmingham, UK, June 2002.

[28] WAycotT, J., SCANLON, E., JonES, A., Evaluating the Use of PDAs as Learning and Workplace Tools: An Activity Theory Perspective, Proceedings of the European Workshop on Mobile and Contextual Learning, pp. 34-35, Birmingham, UK, June 2002.

[29] KeEgan, D., The future of learning: From eLearning to mLearning, available online at http://learning.ericsson.net/leonardo/ thebook/book.html

Received: June, 2003 Accepted: September, 2004

Contact address:

Luigi Colazzo University of Trento Department of Computer and Management Sciences

Via Inama, 5

Trento

Italy

e-mail: colazzo@cs.unitn.it

Andrea Molinari University of Trento Department of Computer and Management Sciences

Via Inama, 5

Trento

Italy

e-mail: amolinar@cs.unitn.it

LUIGI COLAZZO is a professor of database management, and multimedia at the Faculty of Economics. His scientific and research interests have been in the areas of systems for information retrieval, software architectures for knowledge discovery in data base, information systems and systems to support cooperation (CSCW). Since 1989 his work has focused on the use of hypermedia systems and Web-based systems to support the didactic activities. He is member of several professional associations including the IEEE, ACM, AACE, and AICA, Doctor Colazzo has authored numerous papers.

ANDREA MOLINARI has worked as a consultant in the field of analysis and development of information systems and database since 1980 . He has been member of the research group in the field of multimedia and hypermedia systems at the Department of Computer and Management Sciences in Trento, Italy since 1988 and is responsible for distance learning unit at the Laboratory of Maieutics of the University of Trento. 